\title{
A CONSTRUÇÃO DE SENTIDO NA ABORDAGEM SOBRE DIREITOS HUMANOS NO PORTAL CAMPO GRANDE NEWS: mulher criança indígena
}

THE CONSTRUCTION OF MEANING IN THE APPROACH ABOUT HUMAN RIGHTS IN THE CAMPO GRANDE NEWS' WEBSITE: indigenous child woman

\author{
Lynara Ojeda de SOUZA ${ }^{1}$ \\ Universidade Federal de Santa Catarina | Brasil \\ Katarini Giroldo MIGUEL² \\ Universidade Federal de Mato Grosso do Sul | Brasil
}

\begin{abstract}
Resumo
Este artigo problematiza o discurso empreendido pelo portal Campo Grande News (MS) na temática direitos humanos, concentrando-se em subgrupos no contexto das sociedades indígenas: mulheres indígenas, crianças indígenas e mulher criança indígena. Foram levantadas as publicações durante o período de 01 de janeiro a 31 de dezembro de 2016 e selecionado um conjunto de textos, a partir de um percurso temático para analisar o discurso, considerando elementos como os itens lexicais, técnicas argumentativas e os efeitos de heterogeneidade e silenciamento. Com isso, a pesquisa identificou que a cobertura do Campo Grande News foi pautada por uma perspectiva factual e focada em violações, deixando de oferecer ao público as informações necessárias para uma reflexão aprofundada acerca dos direitos humanos.

Palavras-chave

Jornalismo; Campo Grande News; Análise do Discurso; Indígena; Mato Grosso do Sul.

\section{Abstract}

This article problematizes the discourse employed by Campo Grande News (MS) site, concentrating on sub-groups within the context of indigenous societies: women and indigenous children. Publications were collected from January 1 to December 31,2016 and a series of texts were chosen, starting from a thematic pursuit for discourse analysis, considering elements such as lexical items, argumentative techniques and the effects of heterogeneidade and silence. With this, the research identified that the coverage of the Campo Grande News was based on a factual perspective and focussed on violations omitting offering the publica necessary information for a deeper reflection on human rights.

Keywords

Journalism; Campo Grande News; Indigenous; Discourse Analysis; Mato Grosso do Sul.
\end{abstract}

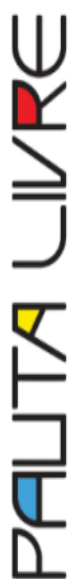

RECEBIDO EM 25 DE NOVEMBRO DE 2019

ACEITO EM 15 DE JULHO DE 2020

\footnotetext{
1 JORNALISTA. Mestre em Comunicação pela Universidade Federal de Mato Grosso do Sul. Doutoranda em Jornalismo pela Universidade Federal de Santa Catarina (UFSC). Contato: Iynaraojeda@gmail.com. 2 Doutora em Comunicação pela Universidade Metodista de São Paulo. Docente nos cursos de graduação em Jornalismo e no Programa de Pós-Graduação, Mestrado em Comunicação, da Universidade Federal de Mato Grosso do Sul (UFMS). Contato: katarini.miguel@ufms.br.
}

João Pessoa - Brasil | ANO 7 VOL.7 N.2 | JUL./DEZ. 2020 | p. 77 a 98 


\section{ÂNEORA}

Lynara SOUSA - Katarini MIGUEL

\section{Do objeto e percurso metodológico}

o se pensar na luta histórica por direitos humanos, é possível
defini-la a partir do reconhecimento da alteridade e suas
especificidades, pautado no compromisso com a inviolabilidade do outro (ARENDT, 2012; COMPARATO, 2010; PIOVESAN, 2007). Desde o advento da Declaração Universal dos Direitos do Homem de 1948 e reiteração na Declaração de Direitos Humanos de Viena de 1993, a sociedade tenta compreender os direitos humanos como a supremacia da dignidade do indivíduo, a partir de um conjunto de normas e mecanismos pretensamente universais ${ }^{3}$.

Atores importantes na promoção dos direitos, os profissionais do jornalismo são capazes de atuar de forma singular e estratégica na luta pela cidadania plena, bem como na denúncia e no enfrentamento da violência. Mas o reconhecimento da complexidade do tema, em tensão com as condições de produção, dificultam uma abordagem a contento entre o ideal preconizado pelas normativas e as especificidades do campo jornalístico. Tais limitações fazem com que os conteúdos noticiosos não alcancem a completude das temáticas e ou sejam meramente episódicos; ora tratados sob as lentes de aumento das editorias policiais, ora minimizados como mais um caso de violação em notas de rodapé. Tal como pondera Charaudeau (2015), a mídia como espelho deformante do mundo, se materializa no plano discursivo.

O presente trabalho reflete os principais resultados de uma pesquisa de Mestrado em Comunicação, que se propôs a investigar a construção de sentido na cobertura jornalística sobre direitos humanos no principal portal de notícias de Mato Grosso do Sul, o Campo Grande News ${ }^{4}$, durante o ano de 2016. Foi

\footnotetext{
${ }^{3}$ Considera-se aqui a ideia de Boaventura Sousa Santos de que não é possível falar em direitos universais sem considerar as especificidades de cada localidade; as concessões convencionais atendem a preceitos hegemônicos, particularmente ocidentais e que facilmente se diferem de concepções de outras culturas (SANTOS, 2009).

${ }^{4}$ Um dos pioneiros em veiculação de notícias exclusivamente pela Internet, o ciberjornal foi fundado em março de 1999, e é o mais acessado do Mato Grosso do Sul, com média de quatro milhões de visitas
} 
realizado um recorte a partir de três grupos vulneráveis e que têm suas condições de vida constantemente ameaçadas: mulher, povos indígenas e crianças; pautado pelo entendimento de que embora não seja possível criar níveis e critérios de direitos humanos mais ou menos violados, pois cada violação possui suas características e se consolida de forma única para o indivíduo que sofre, dentro da realidade local, esses segmentos apresentam índices alarmantes de violência.

Números do Conselho Nacional de Justiça $(\mathrm{CNJ} / 2017)^{5}$ indicam Mato Grosso do Sul como o segundo estado brasileiro com maior incidência de processos de violência doméstica contra a mulher. Já na temática que envolve a população infanto-juvenil, de acordo com Disque Direitos Humanos - 100, serviço de atendimento telefônico que recebe denúncias de violações de direitos, foram realizadas 80,4 mil denúncias de violência contra crianças e adolescentes, sendo que Campo Grande registrou 2.253 ocorrências na Delegacia Especial de Proteção à Criança e ao Adolescente (Depca). De janeiro até abril de 2018, 381 casos de abusos e estupros cometidos contra crianças e adolescentes foram registrados em MS, de acordo com a Secretaria de Estado de Justiça e Segurança Pública (Sejusp). Em relação aos povos indígenas, Mato Grosso do Sul abriga a segunda maior população indígena do Brasil, ao mesmo tempo em que tem o agronegócio como seu principal setor econômico ${ }^{6}$, fatores que transformam o Estado em um palco violento de disputa por terras. De acordo com dados divulgados em 2017 pelo Conselho Indigenista Missionário $(\mathrm{CIMI})^{7}$, foram registrados no Brasil 118 assassinatos de indígenas, além de

mensais, com base no mês de junho de 2020 . Disponivel em: https://br.similarsites.com/site/campograndenews.com.br. Acesso em: 20 jul.2020.

${ }^{5}$ Dados divulgados no relatório "O poder judiciário na aplicação da lei Maria da Penha". Disponível em: http://www.cnj.jus.br/files/conteudo/arquivo/2017/10/ba9a59b474f22bbdbf7cd4f7e3829aa6.pdf. Acesso em: 18 nov.2019.

${ }^{6} \mathrm{O}$ agronegócio responde por $30 \%$ do Produto Interno Bruto (PIB) de Mato Grosso do Sul e o Estado é o $5^{\circ}$ maior produtor de grãos do país. Disponível em: http://www.ms.gov.br/a-economia-de-ms. Acesso em: 20 jul.2020.

7 Números divulgados no relatório "Violência contra os Povos Indígenas no Brasil - Dados de 2016", Disponível em: https://www.cimi.org.br/. Acesso em:18 mai. 2018. O mais recente relatório do Conselho, traz dados de 2018, que reportam 135 assassinatos de indígenas, 38 deles em Mato Grosso do Sul.

João Pessoa - Brasil | ANO 7 VOL.7 N.2 | JUL./DEZ. 2020 | p. 77 a 98 


\section{ÂTEORA}

Lynara SOUSA - Katarini MIGUEL

mais de 100 denúncias oficializadas de violência como atentados, ameaças de mortes e lesões corporais, ao longo de 2016, ano de referência para a presente pesquisa.

O período escolhido também carrega particularidades que denotam a urgência de pesquisas: 2016 foi o ano subsequente à criação da primeira Casa da Mulher Brasileira do país no município de Campo Grande, o que sugere maior incidência de notícias e dados relacionados à violência de gênero nos jornais da capital sul-mato-grossense. $\mathrm{O}$ ano também foi marcado pela criação de uma Comissão Parlamentar de Inquérito (CPI) com o objetivo de apurar atos praticados contra os povos indígenas no período de 2000 a 2015, a chamada de CPI do Genocídio. Além disso, foi o ano subsequente ao primeiro pleito unificado para escolha dos membros dos Conselhos Tutelares no Brasil, o que potencializa as pautas relacionadas à proteção infanto-juvenil na imprensa.

Isso posto, foram quantificadas sobre estes temas no ciberjornal 1.299 matérias, sendo 373 relacionadas à temática mulher, 422 sobre povos indígenas, 504 sobre crianças e adolescentes. A partir desse diagnóstico, selecionou-se os textos jornalísticos a serem lidos na perspectiva da Análise do Discurso (AD), que permite mobilizar conceitos para auxiliar na compreensão do sentido linguístico, articulado com o contexto social no qual o texto é produzido (ORLANDI, 2001). O corpus abarcou um trajeto temático, no caminho proposto por Charaudeau e Maingueneau (2012, p.480) - como "sequência de enunciados significativa do itinerário de um assunto" -, que cruzam dois ou mais subtemas, ou seja, envolvem mais de um grupo vulnerável.

Na limitação deste artigo, são apresentados três textos que pautam a criança indígena, a mulher indígena e a mulher criança indígena; analisados com base em um protocolo de $A D$ focado em dois eixos principais (quatro categorias), sendo: 
1) Itens lexicais e técnicas argumentativas - no sentido de verificar a seleção das palavras utilizadas e como atua na construção de sentido dos textos jornalísticos. Partimos do princípio de que é pela escolha vocabular que o enunciador busca expressar seu ponto de vista em relação ao mundo que o cerca, emitindo juízos de valor. "Trata-se de um campo muito abrangente, mas indispensável, uma vez que o vocabulário, locuções e expressões compõem um conjunto de palavras-chave que, consequentemente, compõem o código linguageiro e clareiam a posição do discurso" (MIGUEL, 2014, p. 31). Nesse contexto também se analisa a forma como são construídos os argumentos e os parágrafos dos textos, bem como o ordenamento estabelecido e a hierarquização constituída no processo argumentativo, que são caras ao universo jornalístico.

2) Heterogeneidade e silenciamento - considerando que o texto jornalístico é atravessado por diferentes discursos, além do enunciador jornalista. Para Charaudeau e Maingueneau (2012, p. 261), "um discurso quase nunca é homogêneo: ele mistura diversos tipos de sequências [...]. Entre os fatores de heterogeneidade, atribui-se um papel privilegiado à presença de discursos 'outros', isto é, atribuíveis a outra fonte enunciativa". Para Orlandi (2001), quando estudamos os discursos, o não dito é tão importante quanto o dito. A pluralidade de vozes se faz relevante na presente pesquisa que aborda temáticas complexas; assim pretende-se "mapear os sentidos presentes no discurso, identificar aqueles sentidos que, embora significativos, estão silenciados [...] ausentes daquele espaço discursivo" (BENETTI, 2010, p.115).

Na sequência, estão os discursos desvelados, apresentados pelos títulos das matérias, com os respectivos hiperlinks para o texto completo. 


\section{0 discurso sobre a criança indígena: "Edemar, 4, mora no hospital para fugir de cultura que poderia matá-Io" (YAHN, 2016)}

\section{Itens lexicais e técnicas argumentativas}

Pode-se observar já no título da matéria a intenção de chamar a atenção do leitor para os aspectos culturais que envolvem a criança indígena: "mora no hospital para fugir de cultura que poderia matá-lo" (YAHN, 2016). Ao afirmar, logo no título, que a cultura à qual Edemar pertence "pode" matá-lo é criada a ideia de que viver entre seu povo é perigoso e fatal, mas não há contextualização sobre tal afirmação em um primeiro momento. A matéria inicia denunciando uma disputa de valores culturais entre a família da criança indígena e os médicos responsáveis pelo seu tratamento. É possível observar esse conflito no primeiro parágrafo que atribui aos profissionais da medicina o verbo "temer", ou na afirmação de que a criança não precisaria permanecer no hospital, mas a internação é a única opção para que ela seja tratada. Tal argumentação vem seguida da fala da cardiopediatra que atende o menino. "Ele corre risco de morte. É preciso manter ele no hospital pela questão cultural, pois, como é indígena, pode não voltar para o tratamento".

Para tentar explicar os aspectos culturais que envolvem o caso e provocam o receio dos médicos, a matéria busca um especialista para comprovar que a preocupação em relação ao tratamento procede: "no caso de Edemar ele acredita que manter a 'internação social' é justificável", afirma o antropólogo, porém, ao explicar as razões, são elencadas pelo especialista justificativas que não estão diretamente relacionadas à cultura de descarte de crianças, ou seja, o antropólogo fala sobre a prática do infanticídio como algo do passado, que não tem mais espaço na cultura indígena local, inclusive por conta da fiscalização de órgãos oficiais. Ao abordar o caso específico de Edemar, a internação social da criança é defendida a partir de argumentos que envolvem o contexto de "instabilidade" familiar em que o menino vive. $O$ texto indica que a família não permitiu que a criança fosse tratada logo que foi diagnosticada, mas tampouco deixa explícito os motivos da negativa por parte 
dos pais. A matéria também afirma que nos primeiros anos de vida o menino não recebeu tratamento para a doença, mas não explica as razões, se por proibição da família ou falta de acesso às políticas públicas.

A cultura indígena é entendida no texto como um problema para a sobrevivência da criança, entretanto o que aparecem são elementos que revelam uma incompreensão em relação a esse povo. Neste sentido, Santos (2002, p. 248), ao explicar a lógica da escala dominante como um das que produzem inexistência, afirma que "as entidades ou realidades definidas como particulares ou locais estão aprisionadas em escalas que as incapacitam de serem alternativas credíveis ao que existe de modo universal ou global". Ou seja, os valores e conhecimentos indígenas são considerados inferiores ou descartáveis, uma vez que não se encaixam no contexto hegemônico ocidental ao qual pertencem os médicos que cuidam do tratamento da criança. Assim, a matéria insiste na ideia de que a cultura indígena é letal ao menino, mas não contextualiza, deixa lacunas que não permitem a apreensão da problemática. O vocabulário e argumentos adotados ao longo da matéria ainda reforçam o papel negligente exercido pelos pais de Edemar: "os pais foram informados sobre a gravidade do caso, mas não permitiram que o filho fosse submetido aos procedimentos", "a família não autorizou", "não recebeu nenhum tipo de acompanhamento ou tratamento nos anos anteriores" (YAHN, 2016).

Há ainda o uso do substantivo "indiozinho" ao falar de Edemar, aparentemente como um apelido diminutivo carinhoso, mas que rotula a criança, pois a utilização da palavra vem carregada de significados que o diferencia das outras crianças, pode-se, assim, entender "indiozinho" como o diferente, o exótico, para além de indicar uma certa vitimização do olhar ocidental. Santos (2002) define tal população como a que vive do "lado de lá" da linha abissal, pois são considerados pelos que vivem do "lado de cá" da linha como não-cidadãos, perigosos e selvagens. A construção argumentativa 


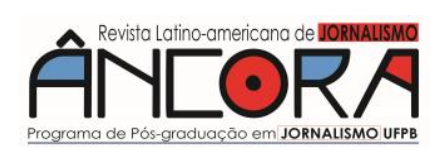

Lynara SOUSA - Katarini MIGUEL

aplicada sugere que pertencer à cultura indígena é ser vítima ou autor de violência.

O hospital é apontado como o lar da criança no texto, considerando que a expressão não indica apenas o local onde se habita, mas envolve relações de afeto, pertencimento e conforto. Tal ideia é reforçada pelas fontes utilizadas: "ele não lembra de outro lar" ou "a equipe toda se envolveu", além disso, os profissionais que atuam no hospital são considerados familiares de Edemar; o que infere-se com frases como: "entre os profissionais que atuam no setor ele já adotou mãe, avó, tias e madrinhas" (YAHN, 2016) ou "a gente tem que cuidar e educar, como se fosse filho mesmo".

Ao mesmo tempo, ao falar da única familiar que acompanha o menino no hospital, sua irmã de 23 anos, o texto deixa explícito a dificuldade dela em se manter ao lado do irmão, como nota-se nos trechos: "para ela viver no hospital é difícil" ou no uso da única fala da jovem ao longo da matéria: "eu não gosto, queria ir embora", o que é justificado em seguida na fala da assistente social. "A situação familiar é bem complicada. Com a morte da mãe quem cuidava dele era o tio, mas o indígena não consegue ficar como acompanhante, é cultural". Os aspectos negativos que envolvem o caso são justificados no texto jornalístico com suporte de falas das fontes entrevistadas. Assim, a notícia é centrada em mostrar Edemar apenas como vítima de uma cultura diferente. Encontra-se, na ocasião, em um lugar de passividade em relação à benevolência dos médicos brancos, e não em um processo de violação e precarização dos direitos dos povos indígenas, que estão à margem da sociedade e sem acesso às políticas públicas básicas, como saúde, educação, assistência social e habitação. A cultura indígena, neste caso, é trazida na perspectiva da desumanização.

\section{Heterogeneidade e silenciamento}

Existe na matéria a presença de vários discursos, além do enunciador jornalista. O texto está apoiado em falas dos profissionais que atuam no 
hospital no tratamento da criança e de um antropólogo para explicar os pretensos riscos da cultura indígena para o menino. A única fonte que fala em nome dos indígenas é a irmã do personagem central, ainda assim, ela aparece somente em um momento do texto e de forma negativa. No momento de explicar os problemas familiares de Edemar, quem fala pela irmã do menino é a assistente social do hospital.

Como observado anteriormente, a matéria desde o título problematiza os aspectos culturais indígenas, porém a etnia de Edemar em nenhum momento é citada e somente no $15^{\circ}$ parágrafo é que a aldeia de onde vem aparece: "deixou a Aldeia Bororó, em Dourados". É preciso salientar a importância dessa informação, pois, segundo Levi (2015), a Reserva Indígena de Dourados é dividida em duas aldeias localizada uma ao lado da outra, a Bororó e a Jaguapiru. E apesar de ser reconhecida a liderança Kaiowá na primeira, a segunda também possui indígenas Guarani, além disso, ainda existem muitas parentelas Kaiowas e Terenas, o que indica um trânsito considerável de indígenas entre as aldeias. Compreender a qual etnia Edemar pertence também nos ajuda a refletir sobre os aspectos culturais que envolvem seu povo.

As descrições etnográficas permitem concluir que a infância se constrói e é construída de maneira peculiar nos diversos contextos da vida dos povos indígenas por meio de complexas técnicas de intervenção sobre os corpos que possuem fundamentos em concepções sociocosmológicas e nas mediações que propiciam entre os grupos sociais e seres espirituais existentes. Cada povo indígena apresenta as especificidades culturais de ordenação da sociocosmoligia e de organização das formas de intervenção sobre corpo/pessoa que influenciam no modo como a infância será fabricada e situam as condições em que as crianças interagem para produzir a cultura local (OLIVEIRA, 2014, p. 70)

Nesse sentido, embora o discurso adotado ao longo do texto faça duras críticas à cultura indígena, em momento algum é ouvido um representante da aldeia ou mesmo um indígena, o especialista atua como "porta-voz". A matéria não contextualiza os aspectos étnicos específicos da criança, desrespeitando a 


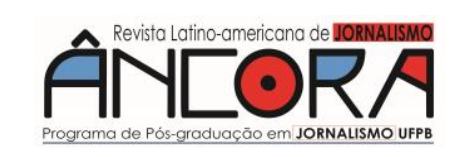

Lynara SOUSA - Katarini MIGUEL

pluralidade esperada em um texto jornalístico ao abordar uma temática complexa, que envolve cultura e sacrifício de crianças, algo ainda desconhecido e incompreendido pelos nossos valores ocidentais.

Outro fato levantado no texto, mas não aprofundado é o assassinato da mãe de Edemar. Em dois momentos a informação aparece na notícia, primeiro na fala do antropólogo entrevistado: "essa criança poderia ser até usada como moeda de troca, por conta da instabilidade familiar e do crime (o pai assassinou a mãe de Edemar) que aconteceu" e, posteriormente, na citação da assistente social. "A situação familiar é bem complicada. Com a morte da mãe quem cuidava dele era o tio, mas o indígena não consegue ficar como acompanhante, é cultural". A complexidade de tal informação aponta para as razões da negligência no tratamento da doença da criança, uma vez que a família vive em meio à uma situação de extrema violência, porém, essa problematização não foi observada. Também fica evidente a responsabilização apenas da família pelo tratamento tardio da criança, mas não é questionado o "dever da comunidade, da sociedade em geral e do Poder Público de assegurar, com absoluta prioridade, a efetivação dos direitos referentes à vida", conforme preconizado no artigo $4^{\circ}$ do ECA (Estatuto da Criança e do Adolescente). Considerando os aspectos legislativos, o texto deveria questionar a não interferência do Estado e demais setores da sociedade quando foi identificada a falha da família nos cuidados com o garoto, pois, como consta no artigo do Estatuto, também são responsáveis pela garantia dos direitos humanos da criança.

Os discursos sobre a mulher indígena: "Sob ameaça de despejo, símbolo da resistência é Damiana e seus 70 anos" (MACIULEVICIUS, 2016)

\section{Itens lexicais e técnicas argumentativas}

O presente conteúdo jornalístico analisado sobre mulher indígena possui elementos interpretativos, constatados a partir da própria estrutura textual, ou tipologia de procedimentos discursivo, segundo Charaudeau 
(2015), em uma escritura midiática caracterizada como reportagem, de um subgênero perfil, que faz uso de recursos designativos, figuras de linguagem, elementos de dramatização, para atender as condições de credibilidade, mas também tocar a afetividade do leitor. Trata-se de uma reportagem publicada em uma editoria específica do portal de notícias, intitulada Lado $B$, que prioriza reportagens e conteúdos de caráter comportamental.

Ao longo do texto, é notório o espaço dado para as falas da personagem central e a narração de sua história, outra característica de reportagens, que, segundo Leandro e Medina, (1973), pretendem dar valor ao humano no acontecimento jornalístico. O uso de palavras como "símbolo", "resistência", "firme" e "força" funcionam como adjetivos e relacionam à Damiana a ideia de mulher forte, mesmo tendo mais de 70 anos, elementos que compõem a metáfora da guerreira. Confere-se o desdobramento dessas colocações em argumentações, como: "Damiana esquece a idade, mas sabe de cor as mortes que o solo onde pisa já viu...", "é miúda em tamanho, mas firme nas palavras e na postura que adota" e "tem força no sangue vermelho e nos olhos". Mesmo no título, há o uso desses vocábulos que anunciam a expressividade da personagem e o drama em que vive. "Sob ameaça de despejo, símbolo da resistência é Damiana" (MACIULEVICIUS, 2016).

A reportagem no primeiro parágrafo informa qual etnia a personagem pertence, Guarani-Kaiowá, o que auxilia na compreensão da importância da figura feminina de Damiana para seu povo, principalmente nas retomadas de terras, assunto que é gancho da reportagem, por abordar o fim do prazo dado pela justiça para que a indígena saia do território que reivindica, o Apyaca'í. A terra é elemento fundador e mantenedor da cultura indígena.

Talvez seja difícil de perceber (difícil para a sociedade dos não indígenas em geral) o quanto elas são fundamentais para que a organização social dos Guarani e Kaiowá permaneça estruturada, mas a partir do momento que se convive com elas, pesquisa-se trabalhos sobre etnologia e gênero [...] um outro olhar se lança para outros enlaces teóricos. A retomada se dá a partir de ações de vários sujeitos, com papéis que se complementam sob uma hierarquia que 


\section{ÂNEORA}

Lynara SOUSA - Katarini MIGUEL

não a de estamentos que se sobrepõem sem reciprocidade de nosso modelo militar. O pessoal/doméstico é político, slogan das feministas da década de 1970, sim, e o doméstico das mulheres Guarani e Kaiowá é público, porque a partir das relações da família extensa não se organiza apenas a parentela, mas organiza-se a luta dos Guarani e Kaiowá pela demarcação de seus territórios tradicionais (ANZOATEGUI, 2017, p.110)

Nesse sentido, a reportagem faz descrições de espaço, explicando o local em que Damiana se encontra: "sete quilômetros do centro de Dourados", "entre o mato de um riacho poluído e uma plantação de cana", para que o leitor consiga visualizar a terra reivindicada pelos indígenas. Além disso, explica que no mesmo local estão enterradas "perdas" de Damiana, retomando a importância do lugar para a personagem que afirma ser esse também um dos motivos de se manter no local: "por isso eu não quero sair daqui não. Eu não vou sair. Eu tenho coragem...." A escolha por um vocabulário que reforce argumentos sobre a força da personagem ao mesmo tempo em que explica as razões de permanecer no local, mesmo a justiça tendo determinado a saída, auxilia na compreensão da forte relação de Damiana com seu tekoha, ou seja, sua terra tradicional.

Ao demonstrar os anos de disputa pela terra ocupada por ela e sua parentela, a jornalista destaca a diferente forma da cultura indígena se relacionar com a terra, como faz ao argumentar: "os ataques que a comunidade relata ter vivido já somam uma década [...]. Este será o quinto despejo de um povo que tem uma concepção muito diferente sobre a terra. A veem como lar" (MACIULEVICIUS,2016). Fato reforçado em seguida pela fala de Damiana: "a terra é para criar as coisas, plantar as coisas para recuperar. Perdemos tudo, plantamos tudo [...] tekoha pra gente é viver nossa família". Ou ao afirmar que só sairá das terras morta: "a hora que me matar o fazendeiro, eu vou ficar junto lá do meu pai", o que desponta ainda o perigo que é estar em meio ao conflito por terras. 
Heterogeneidade e silenciamento

O discurso da personagem apresenta espaço e importância ao longo de todo o texto, pois é Damiana quem narra o drama vivido há 25 anos na luta por seu tekoha. "Eu não vou baixar a cabeça. Vamos à luta. Vamos levar para a frente a luta". É ela quem explica a importância do território, e que enumera a quantidade de vezes em que foi despejada: "Não tenho medo da polícia, do choque, eu não tenho medo. Já foram quatro vezes". Além do discurso de Damiana, o texto traz entrevista com especialista que também explica a importância dela como mulher líder no território em que se encontra.

$\mathrm{Na}$ reportagem, as fontes especialistas aparecem para corroborar o importante papel de Damiana em Apyaca'íe a disputa violenta pelas terras. As citações das fontes revelam: "ela em Dourados é símbolo por estar disposta a enfrentar desde sempre as autoridades e ficar ali, no seu território". Assim, todos os depoimentos acabam dando sentido à última frase do texto: "E Damiana vai resistir, mais uma vez" (MACIULEVICIUS, 2016).

Outro recurso utilizado na reportagem para mostrar o protagonismo de Damiana são as redes sociais. No texto aparecem mensagens que circulam na internet relatando respeito e admiração pela indígena, além do apoio diante de mais um despejo: "uma mulher que promete enfrentar todas as estruturas em defesa de seu território"; "ela é o ser humano mais iluminado e forte que conheci nas últimas décadas".

Ainda que o conteúdo se destaque no esforço de entender a sujeita e ter empatia ao narrar sua história no conflito de terras, há lacunas ao não explicar o percurso histórico e o processo de retomada das terras em que Damiana vive, o que limita a compreensão da temática. Além disso, colocar a mulher indígena como guerreira pode ser limitador e abstrato, reforçando ideias figurativas da posição indígena, inclusive de resiliência ao sofrimento, 


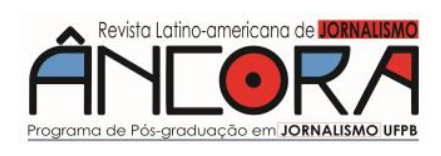

Lynara SOUSA - Katarini MIGUEL

não confrontando o ciclo de violências, já que faz parte de uma pretensa história de superação: mais uma vez ela vai (ter que) resistir!

O discurso sobre a mulher criança indígena: "Estuprada e morta, menina de 3 anos estaria sendo agredida há 7 meses" (RODRIGUES, 2016).

\section{Itens lexicais e técnicas argumentativas}

O texto analisado é factual e narra uma tragédia que abarca os três eixos da presente pesquisa: mulher, criança e indígena. O título da matéria não revela que a criança do fato é indígena: "menina de 3 anos", há também o uso do verbo "estar" no condicional (futuro do pretérito): "estaria sendo agredida", o que se reconhece como uma das técnicas jornalísticas para não enfatizar, ou mesmo confirmar informação, e comprometer a suposta neutralidade no processo de construção da notícia, mesmo que ao longo do texto sejam utilizadas fontes que comprovam as agressões.

A matéria inicia com a escolha de um vocabulário que busca chamar a atenção para a gravidade da violência sofrida pela criança: "agredida", "queimada", "estuprada" e "até a morte" aparecem logo na primeira frase do texto. Somente na segunda frase é informado que a menina de três anos é indígena da Aldeia Bororó, localizada na Reserva Indígena de Dourados. $\mathrm{O}$ uso de palavras que reforça a tentativa de destacar a violência aparece ao longo de todo texto, como "brutalidade" e "horrível", incluindo no intertítulo o advérbio de modo "brutal". O texto descreve com detalhes a situação de violência em que a criança vivia: "encontraram a menina com a mandíbula quebrada, com hematomas em todo o corpo e sinais de violência sexual" (RODRIGUES, 2016).

A matéria apresenta uma construção argumentativa centrada na descrição dos fatos. No primeiro parágrafo já consta a informação de que a violência teve início quando a criança foi morar com os tios, o que faz deles suspeitos. Os dados apresentados estão baseados na informação policial e 
as expressões escolhidas são baseadas em documentos do tipo, como: "decretou prisão preventiva". A fonte oficial entrevistada é a delegada responsável pelo caso e, mesmo com os suspeitos negando o crime e estando em fase de investigação, afirma que, baseada em testemunhas, os tios são os agressores. Isso sinaliza para a responsabilização do casal por parte das autoridades, e reproduzida no texto jornalístico a partir do uso das citações oficiais: "uma testemunha está sendo fundamental para que tenhamos certeza do fato, mas ainda queremos descobrir o motivo de tanta brutalidade". A entrevistada também destaca a gravidade do fato: "é um crime brutal, horrível, que não pode ficar impune e vamos apurar com prioridade". Embora a versão oficial afirme a intenção de priorizar a resolução desse caso, como observado nos dados apresentados, a violência sexual ainda apresenta números urgentes no Mato Grosso do Sul, sendo uma violação muitas vezes invisível e negligenciada por parte das instituições que atuam na defesa e responsabilização de ocorrências de abuso sexual cometido contra crianças.

A citação da delegada ainda aponta as responsabilidades de profissionais que atuam na rede básica de atenção à saúde na identificação de situação de violência. "No local não há vizinhos próximos, mas agentes de saúde e pessoas que costumam acompanhar os indígenas dizem que não viam a criança...", o que destaca a necessidade da intervenção das políticas públicas no enfrentamento à violação de direitos. Nota-se o mesmo contexto quando no texto informa que os policiais acompanharam membros do Conselho Tutelar até o local em que a criança morava, assim como na frase: "a delegada disse que vai ouvir agentes de saúde, do CRAS (Centro de Referência de Assistência Social), da aldeia, familiares..." (RODRIGUES, 2016).

Outros atores importantes que aparecem no texto são as lideranças indígenas, que, segundo a notícia, auxiliaram na busca pelos agressores: 


\section{ÂNEORA}

Lynara SOUSA - Katarini MIGUEL

"Rosiane [...] e o marido fugiram antes da chegada da polícia, mas com ajuda de lideranças da reserva indígena os dois foram localizados" (RODRIGUES, 2016). As lideranças que aparecem como indivíduos fundamentais para o andamento do caso, já que localizaram os agressores, não são identificadas.

No último parágrafo, a matéria explica que os suspeitos foram presos em "flagrante por estupro e lesão corporal seguida de morte". As palavras estupro e violência sexual aparecem do título à última frase, porém esse tipo de violação foi pouco explicado e aprofundado e os termos só são utilizados quando auxiliaram a destacar a gravidade do caso, deixando de problematizar a temática.

\section{Heterogeneidade e silenciamento}

Mesmo a matéria tratando de um assunto complexo que envolve três subtemas: mulher, indígena e criança, e cada um desses grupos possui aspectos singulares de ser e existir, sofrem violações de direitos de forma também muito específica, apenas uma fonte é utilizada para dar entrevista e, ainda assim, apenas para auxiliar na descrição do crime e dar a versão oficial da polícia, uma vez que é justamente a delegada responsável pelo caso. Desse modo, considera-se importante mais fontes que possam dar a dimensão conceitual do ocorrido e não que torne sensacional a violência que a criança sofreu, como fica explícito no uso das palavras "brutal" e "horrível", que acaba não auxiliando na problematização e reflexão sobre violação de direitos.

Ainda há a intenção da matéria, a partir de dados da delegacia, em identificar os agressores, que são os tios da criança, porém não questiona os motivos da criança ter saído da casa dos antigos cuidadores, nem explica com quem a menina morava antes, se com os pais, avós e se já vivia em uma situação de vulnerabilidade. A história e quem era a criança não aparecem no texto, somente a violência que ela sofreu, dando 
protagonismo aos suspeitos em vez de humanizar a vítima e as pessoas que sofrem com sua perda. $O$ texto tampouco considera as falhas na proteção à criança, pois ao responsabilizar somente os tios, deixa de problematizar o não cumprimento do ECA no que diz respeito ao papel do Poder Público e da sociedade no zelo pela garantia da integridade da menina, conforme artigo $5^{\circ}$. "Nenhuma criança ou adolescente será objeto de qualquer forma de negligência [...] exploração, violência, crueldade [...], punindo na forma da lei qualquer atentado, por ação ou omissão, aos seus direitos fundamentais". No texto é indicado que testemunhas, inclusive atuantes na política pública de saúde, devem ser capacitadas para identificação de ocorrências de violações de direitos, pois acredita-se que a criança sofria agressões há meses. Contudo, não foi apurado o tempo exato levado para que as autoridades atuassem na ruptura da violência, preferiu deixar subtendido que foi preciso encontrar a criança em estado grave para que houvesse uma interferência, colocando em xeque a estrutura de acolhimento.

A notícia faz uma abordagem policial puramente descritiva, notificada pela gravidade do caso, mas não se atenta para a abrangência das problemáticas. $\mathrm{O}$ tom sensacionalista ainda aproxima da ideia do indígena como selvagem, brutais, cruéis e enviesa a interpretação.

\section{Das discussões e considerações possíveis}

Este artigo contempla a análise de três textos que cruzam os subtemas criança indígena, mulher indígena, mulher criança indígena para revelar a construção de sentido na abordagem jornalística de direitos humanos no Campo Grande News, ainda que em um veículo específico e com recorte delimitado. Neste momento coloca-se as considerações pautadas nos textos aqui analisados e também a partir de uma perspectiva ampliada, proporcionada pelas investigações anteriores. 


\section{ÂNEORA}

Lynara SOUSA - Katarini MIGUEL

O perfil factual e informativo apareceu de modo imperativo, sendo que de todos os conteúdos selecionados, no trajeto temático adotado, apenas um apresentou elementos interpretativos e melhor contextualização, possuindo, assim, característica de uma reportagem: "Sob ameaça de despejo, símbolo da resistência é Damiana e seus 70 anos" (MACIULEVICIUS, 2016). A maior parte traz textos com abordagens policiais e sem aprofundamento; pautada em violações de direitos, evidenciando que tais grupos ocupam a imprensa quando sofrem violência, contudo, a abordagem feita não considera os aspectos que auxiliam a compreender a relação existente entre violência e direitos humanos.

Nenhuma das notícias apresenta dados de fontes documentais, tampouco cita as legislações vigentes que protegem os grupos analisados, o que revela um certo descuido editorial ou a falta de conhecimento por parte dos jornalistas. Nota-se, nessa esteira, a ausência de pluralidade no conteúdo jornalístico, já que os textos apresentam poucas fontes pessoais e um especialista é consultado apenas na primeira matéria aqui analisada: "Edemar, 4, mora no hospital para fugir de cultura que poderia matá-Io" (YAHN, 2016). Por serem conteúdos, aparentemente, pautados em boletins de ocorrência, há a predominância do uso de delegados e investigadores como fontes, prevalecendo somente a versão da polícia e reforçando o tom policialesco, e os aspectos meramente descritivos, deixando de abordar e contextualizar a história das personagens, além de negligenciar os desdobramentos de cada caso, ou seja, tratam de forma episódica e como acontecimentos isolados. Existe, sobretudo, real ausência de fontes, por exemplo, que apresentem a perspectiva dos grupos violados, o que corrobora o silenciamento. Mas vale a atenção ao exemplo positivo colocado, justamente o texto sobre a líder indígena Damiana, em que a própria personagem consegue narrar seu drama.

Não obstante os profissionais da imprensa possam ser reconhecidos como capazes de interpretar e compartilhar com o público experiências desconhecidas e, muitas vezes, invisibilizadas, é fato que constroem uma 
realidade a partir de suas experiências e valores, com isso, os aspectos culturais e os padrões ideológicos, presentes na sociedade, se impõem nas condições de produção. Os jornalistas estão imersos e suscetíveis a reproduzirem elementos do contexto social em que vivem, mesmo que acreditem, apoiados na técnica de produção de notícia, por exemplo, numa possibilidade de anulação de suas crenças. Mato Grosso do Sul, como já colocado, é um Estado que favorece o agronegócio, em detrimento de seus povos indígenas, se consolida economicamente em terras originárias (CIMI).

Existe, nesse contexto, uma distância considerável entre o ideal e a prática na abordagem de direitos humanos no Campo Grande News. Ponderase que as rotinas de trabalho, a exigência de produções factuais e ágeis, cada vez mais constantes e atendendo a uma dinâmica mercadológica, afetam diretamente uma cobertura jornalística aprofundada e complexa como exige as temáticas estudadas. Os fatores são muitos, difíceis de elencar com exatidão e fogem da alçada deste artigo: vão desde procedimentos editoriais, cerceamentos políticos e econômicos, condições temporais e espaciais, a falta de conhecimento e distorções involuntárias (ou não).

A pesquisa revela, sobretudo, a predominância de discursos que estigmatizam pessoas que têm seus direitos violados. Ao reproduzir padrões ideológicos que veem os indígenas como exóticos, negligentes e oriundos de uma cultura violenta e desconhecida, o ciberjornal reforça a lógica de nãoexistência provocada pela ignorância e o não reconhecimento do outro como sujeito pleno de direitos.

Os resultados desse trabalho não estão isolados, reiteram uma série de violações presente na construção de sentido sobre o indígena na imprensa sulmato-grossense, já evidenciada por outras pesquisas em momentos e com corpus distintos. Otre (2014), por exemplo, realizou uma análise quantiqualitativa nos sites de notícias Campo Grande News e o Midiamax na cobertura de um caso, ocorrido em 2001 - a invasão por pistoleiros do 


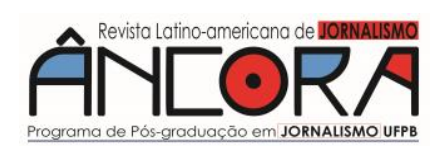

Lynara SOUSA - Katarini MIGUEL

acampamento Tekoha Guaiviry, em Amambai (MS) -, que culminou no assassinato de seu líder, Nísio Gomes. Os resultados revelaram que a produção jornalística optou pelo silenciamento das vozes indígenas ou "pela exploração político-partidária do tema" (OTRE, 2014, p. 2). Sobre o mesmo caso, Queiroz (2014) também constatou a dinâmica de invisibilidade. Nos textos produzidos pelos ciberjornais locais, a população indígena teve sua versão sempre representada por órgãos oficiais. Monteiro (2017) identificou em dissertação de mestrado, também realizada com foco nos portais de notícias locais, a visão estereotipada do indígena como selvagem, atrasado e violento, no recorte com os Kaiowás e Guaranis. O conteúdo jornalístico abriu espaço, na maior parte do tempo, para o discurso de ruralistas que contestam os territórios indígenas.

Nesse sentido, esta pesquisa é mais um resultado que problematiza a atuação da imprensa e as responsabilidades do jornalista na defesa de direitos humanos, e reforça a necessidade de vigilância na cobertura de fatos que refletem diretamente na visão da sociedade sobre os povos indígenas.

\section{Referências}

ANZOATEGUI, Priscila de Santana. "Somos todas Guarani-Kaiowá": entre narrativas (d)e retomadas agenciadas por mulheres Guarani e Kaiowá sul-mato-grossenses. 161f. Dissertação. (Mestrado em Antropologia) Universidade Federal da Grande Dourados, Dourados, 2017.

ARENDT, Hanna. Origens do Totalitarismo. São Paulo: Companhia das Letras, 2012.

BENETTI, Marcia. Análise do Discurso em jornalismo: estudo de vozes e sentidos. In: LAGO, Claudia; BENETTI, Marcia (orgs). Metodologia de pesquisa em jornalismo. 3. Ed. Petrópolis: Vozes, 2010. BRASIL. Constituição (1988). Constituição da República Federativa do Brasil: promulgada em 5 de outubro de 1988. Braślia - DF, 1988. Disponível em:<http://www.planalto.gov.br/ccivil_03/constituicao/constituicao.htm>. Acesso em: 10 nov. 2019. CHARAUDEAU, Patrick. Discurso das mídias. São Paulo: Contexto, 2015. CHARAUDEAU, Patrick; MAINGUENEAU, Dominique. Dicionário de análise do discurso. São Paulo: Contexto, 2012 COMPARATO, Fábio Konder. A afirmação histórica dos direitos humanos. São Paulo: Saraiva, 2010. 
CONSELHO INDIGENISTA MISSIONÁRIO. Violência contra os povos indígenas no

Brasil: Dados de 2016. [S.I.]: Cimi, 2016. 148 p. Relatório. Disponível em: https://www.cimi.org.br/pub/relatorio/Relatorio-violencia-contra-povosindigenas_2016-

Cimi.pdf. Acesso em: 18 nov. 2019.

CONSELHO INDIGENISTA MISSIONÁRIO. Observatório da Violência

contra os Povos Indígenas no Brasil. Disponível em:

https://cimi.org.br/observatorio-da-violencia/ Acesso em: 20 jul.2020.

MACIULEVICIUS, Paula. Sob ameaça de despejo, símbolo da

resistência é Damiana e seus $\mathbf{7 0}$ anos. Disponível

em:<https://www.campograndenews.com.br/lado-b/comportamento-23-08-

2011-08/sob-ameaca-de-despejo-simbolo-da-resistencia-e-damiana-e-seus-

70-anos>. Acesso em: 18 nov. 2019.

MEDINA, Cremilda de Araújo; LEANDRO, Paulo Roberto. A arte de tecer o

presente: jornalismo interpretativo. São Paulo: Edição dos Autores, 1973.

MIGUEL, Katarini. Pensar a cibercultura ambientalista: comunicação,

mobilização e as estratégias discursivas do Greenpeace Brasil. 266 f. Tese

(Doutorado em Comunicação Social) - Faculdade de Comunicação da

Universidade Metodista de São Paulo, São Bernardo do Campo, 2014.

MONTEIRO, Everson. Os cibermeios e a representação dos povos

indígenas Kaiowá e Guarani em Mato Grosso do Sul: Estudo de caso

da retomada do território indígena Yvy Katu. 2017, 169f. Dissertação

(Mestrado em Comunicação). Programa de Pós-Graduação em Comunicação, Universidade Federal de Mato Grosso do Sul, Campo Grande, MS. 2017.

OLIVEIRA, Assis da Costa. Indígenas crianças, crianças indígenas:

perspectivas para construção da doutrina da proteção plural. Curitiba: Juruá, 2014.

ORLANDI, Eni Pulcinelli. Análise de Discurso: princípios e

procedimentos. São Paulo: Pontes, 2001.

OTRE, Maria Alice Campagnoli. Representação midiática, identidade indígena e o jornalismo no Mato Grosso do Sul. Revista Científica de Ciências

Aplicadas. Disponível em:

http://faip.revista.inf.br/imagens_arquivos/arquivos_destaque/3TrBTineVbRw 7Us_201 4-6-30-9-52-40.pdf. Acesso em: 14 nov.2019.

PIOVESAN, Flavia. Direitos Humanos e o Direito Constitucional

Internacional. 8aed. São Paulo: Saraiva, 2007.

QUEIROZ, Tatiane Karina Barbosa de. Discursos e sentidos na cobertura jornalística: "o caso Guaiviry em Mato Grosso do Sul". 2014, 97f.

Dissertação (Mestrado em Estudos de Linguagens). Programa de Pós-

Graduação em Estudos de Linguagens, Universidade Federal de Mato Grosso do Sul, Campo Grande, MS. 2014. 


\section{AN[ORA}

Lynara SOUSA - Katarini MIGUEL

RODRIGUES, Luana. Estuprada e morta, menina de 3 anos estaria sendo agredida há 7 meses. Disponível em:

$<$ https://www.campograndenews.com.br/cidades/interior/estuprada-emorta-menina-de-3-anos-estaria-sendo-agredida-ha-7-meses>. Acesso em: 21 nov. 2019.

SANTOS, Boaventura de Sousa. Direitos humanos: o desafio da interculturalidade. 2009. Disponível em:

http://www.boaventuradesousasantos.pt/media/Direitos\%20Humanos Revis ta\%20Direitos\%20Humanos2009.pdf. Acesso em: 20 jul. 2020.

SANTOS, Boaventura de Sousa. Para uma sociologia das ausências e uma sociologia das emergências. Revista Crítica de Ciências Sociais, n. 63, out., 2002, p. 237-280. Disponível em: http://rccs.revues.org/1285. Acesso em: 20 jul. 2020.

YAHN, Natalia. Edemar, 4, mora no hospital para fugir de cultura que poderia matá-lo. Disponível em:

https://www.campograndenews.com.br/cidades/edemar-4-mora-no-hospitalpara-fugir-de-cultura-que-poderia-mata-lo. Acesso em: 21 nov. 2019. 